\title{
MAINTAINING THE APPROPRIATE LEVEL OF QUALITY IN THE ASPECT OF MACHINERY AND EQUIPMENT SAFETY IN FOOD INDUSTRY
}

doi: 10.2478/cqpi-2019-0017

Date of submission of the article to the Editor: 08/04/2019

Date of acceptance of the article by the Editor: 14/05/2019

\author{
Agata Kielesińska1'-orcid id: 0000-0001-9974-7961 \\ Miroslav Pristavka ${ }^{2}$-orcid id: 0000-0002-7957-4765 \\ ${ }^{1}$ Czestochowa University of Technology, Poland \\ 2 Slovak University of Agriculture in Nitra, Slovakia
}

\begin{abstract}
In the paper, the problem and importance of maintaining an appropriate level of quality in relation to labor protection in the light of EU and national legal standards have been presented. Maintenance of machines and, consequently, stability in the field of process quality is identified on the basis of specific management requirements according the machinery safety in food industry, also with respect to the sphere of their construction, production, distribution, and in particular exploitation. The food industry on global markets is characterized by a large variety of consumers. Therefore, both needs and requirements can have a very wide range, also with regard to quality criteria, care for the natural environment, development of technologies as well as new products introduction. Trends defining dynamics and competition in the food industry include a large number of factors, that require effective management, e.g.: quality ingredients of foodstuffs, preparation of products, maximum product safety as a measure of quality, application of modern production technologies (fast filling and packaging installations). Care for the safety of machinery and equipment used in industry and food processing is a guarantee of manufacturing products of the highest nutritional quality for consumers. With regard to ensuring the safety and quality of food products, in the paper the general principles in risk assessment and the technical measures to improve the safety of machines during their use have been presented.
\end{abstract}

Keywords: food industry, machinery, hygiene package, exploitation, production quality

\section{INTRODUCTION}

The food industry is an important branch of the economy, which manufactures products and semi-finished products for consumption, such as: meat, dairy products, bread, confectionery, alcoholic and non-alcoholic beverages, etc. The industry includes: slaughterhouses, fish processing plants and meat, dairies, bakeries, sugar factories, distilleries, breweries, mills, juice factories and fruit and vegetable 
processing, confectionery and tobacco factories. it should be noted that all countries care for the appropriate level of development of the food industry, because it becomes the determinant of the state's economic condition. and in addition, a well-developed food industry is able to ensure state security in the food demand of citizens and launch of a global market for food products (Barkema et al., 2015; Baryshnikova et al., 2019; Kielesińska, 2018; Martinsa et al., 2017). Ruthlessly in world literature, the quality of food is perceived as equal to food safety (both in the production zone and in the post-production zone - consumption) (Khan et al., 2017; Piras et al., 2015; Pouliot and Sumner, 2008; Yaseen et al., 2017).

The EU's document on food quality and safety is the set of the legal framework for food hygiene and safety. Rules have been adopted in April 2004 by the European Parliament and the Council (Regulation (EC) No 852/2004, 853/2004 and 854/2004). Unified food recipes, creating the so-called "The Hygiene Package" includes four regulations laying down the rules of hygiene of foodstuffs, as well as the rules of conduct of supervisory authorities for food industry operators, as shown in Fig. 1.

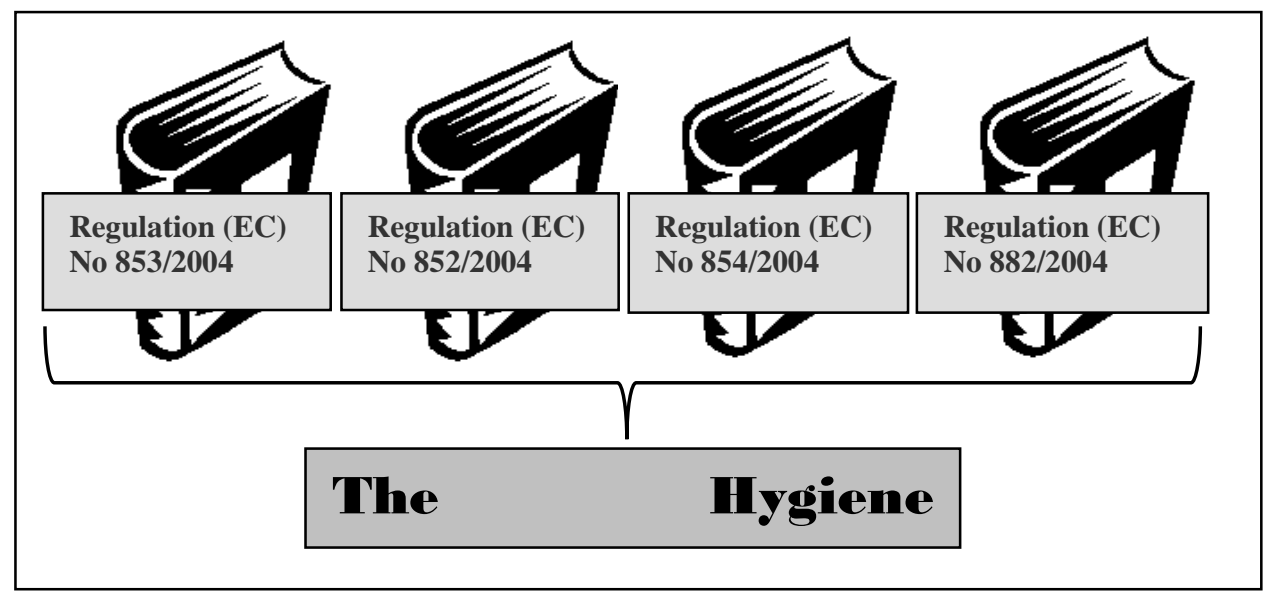

Fig.1, A set of selected EU regulations approved by the European Parliament and the Council - food regulations forming the "Hygiene Package"

Source: own study based on www.pis.gov.pl and www.europarl.europa.eu/factsheets/en

These regulations clearly direct the responsibility for food safety and hygiene throughout the food chain to food businesses, regardless of the position they occupy in the food chain. Supervision of these commitments shall be exercised by a number of government agencies (usually by the Office. Food and Veterinary Office). The legislation on food safety in the EU is comprehensive and covers food, animal feed, extends to food hygiene, and most importantly uses the same high standards throughout the entire EU. In addition, the provision of standards causes a workable situation in both micro and macroeconomics (Andersson, 2019).

The implementation of safety requirements included in the European Union directives and national regulations regarding the construction and use of machines is aimed at ensuring safety and protection of human health in the environment of its work and ensuring free circulation of machinery on the European market. The EU directives on the safety of the use of machinery and equipment are divided into two groups:

1. Economical, related to the "new global approach", refer to the design, production and placing of machines on the market - their recipients are designers, constructors and producers - Directive 2006/42/EC of the European 
Parliament and of the Council of 17 May 2006 on machinery, and amending Directive 95/16/EC (recast).

2. Social, concern employers and set minimum health and safety requirements that employers should provide employees with at work - Framework Directive 89/391/EEC which include different groups of workers (self-employed, armed forces, domestic workers, e.t.c.) as well as the use of work equipment Directive 89/655/EEC amended by Directive 2001/45/EC and Directive 2009/104/EC.

\section{METHODOLOGY OF RESEARCH}

In the study the desk research method, as method of information analysis has been used. The desk research tests presented in the paper include compilation, mutual verification and processing of legal documents and safety requirements used in enterprises from the food industry. This issue has been regulated in the light of directives and harmonized national laws of the member state of the European Union. The problem of machine safety has been considered in respect to the basic EU directives.

\section{RESULTS AND DISCUSSION}

The specificity of machines used in the food industry results from the necessity to ensure safety in two areas: safety related to the personnel operating the machine and food safety, (ensuring that the food is not contaminated during the processing). Safety requirements related to machine operation are described in the attachment in section 2.1. Machinery Directive, in harmonized standards and numerous regulations. It is clear from the text of the directive that the machine must be designed and constructed in such a way that all its components can be dismantled and cleaned thoroughly at every application. If, for technical reasons, this condition cannot be met, it is necessary to indicate the obligation to use disposable equipment. In addition, all surfaces in contact with food must be smooth and free of gaps. Low surface roughness will prevent the accumulation of organic substances and limit the multiplication of undesirable bacteria and microorganisms. Machine surfaces that come into contact with food and its raw materials must be easy to clean and disinfect, and the radius of all curvatures of the internal surfaces must enable their thorough cleaning. It is also required to completely remove liquids, gases and aerosols from food, as well as liquids used for cleaning, disinfecting and rinsing. The machine must be designed and constructed in such a way that no substances or living organisms, in particular insects, cannot penetrate into working areas, and no organic substances (organic or hazardous) could not be accumulated.

\subsection{Legal regulations in relation to quality and safety}

The appropriate level of machine hygiene is specified in EN 1672-2, which specifies the safety and hygiene requirements for machines used to prepare and food processing, in order to eliminate or reduce the risk of infection or injury. One aspect of the discussed standard is risk and threat assessment (for service and food). Standard additionally specifies the requirements for the construction materials, joints and surfaces, according to the areas of their destination, with particular emphasis on the food zone or food chambers, i.e. materials with direct contact with food. In food spaces, the used materials should be resistant to corrosion, should be non-toxic and, 
as far as possible, non-absorbable, and these materials should not migrate to food (both heavy metals and other substances having an adverse effect). In addition, the standard describes the principles of joints, edges and outflows construction, with particular emphasis on the possibility of cleaning. Other specific requirements for food contact materials are included in the regulations specifying acceptable levels of heavy metals and acceptable levels of their migration. The safety of materials for contact with food is regulated by Reg. (EC) No. 1935/2004 of the European Parliament and of the Council of 27 October 2004 on materials and articles intended to come into contact with food, both for direct and indirect contact with food including (Knop and Mikulová, 2019; Nerín et al., 2007; Yam et al., 2005): packaging materials, household appliances (e.g. kitchen robots, grinders, refrigerators), dishes and tableware, parts of machines and devices; conveyor, pipes and tanks used in the food industry.

\subsection{Food Safety Management Systems}

Food Safety Management System (FSMS), which takes into account ISO 22000: 2005, ISO / TS 22002-1: 2009 and FSSC 22000 requirements (Figure 2). This standard defines international and national requirements for food health safety, and supports the production of food that is safe for the health of consumers - i.e. that closely monitors stages of the production process where the product may be contaminated with harmful microorganisms (e.g. bacteria and fungi), chemical substances (e.g. washing agents, mold toxins) or the introduction of physical impurities.

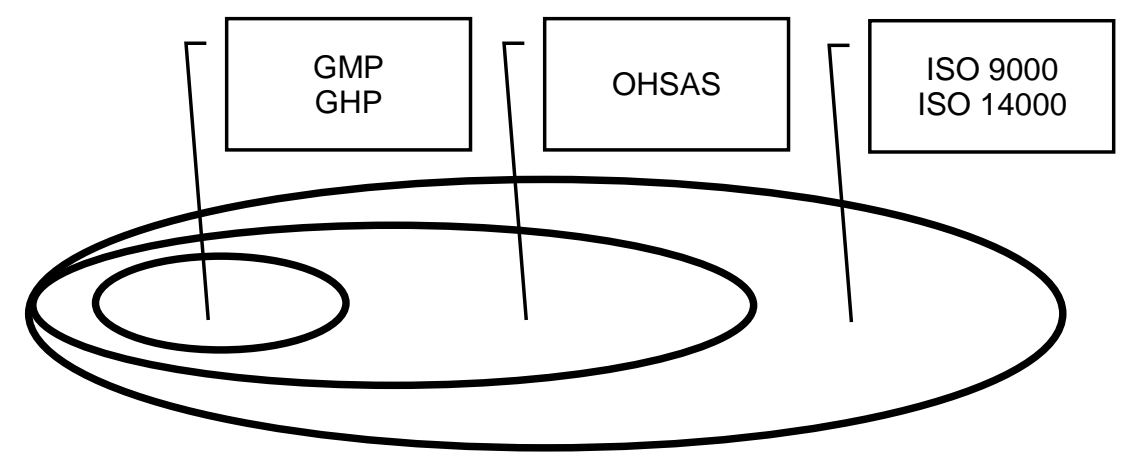

ISO 22000

Fig. 2 General structure of the ISO 22000: 2005 standard (GMP - Good Manufacturing Practice, GHP - Good Hygienic Practice)

Source: own study based on ISO 22000: 2005 standard

As part of quality assurance and food safety (apart from the general requirements of the Labor Code), in enterprises with foreign capital it is often also certified the Occupational Health and Safety Management System according to the OHSAS 18001: 2007 standard, which presents the requirements in order to enable the organization to define policies and objectives in this area - including the obligation of organizations (enterprises) to prevent accidents at work and professional diseases. The OHSAS promotes striving for constant improvement of safety, compliance with regulatory requirements, continuous improvement of performance in health and 
safety, ensure that appropriate measures to protect employees and staff qualifications and hygiene.

Activities in the area of required occupational health and safety prevention in the food industry include, among others:

1. Recommendations for constructors and manufacturers of devices and machines, in the field of machine hygiene according to EN 1672-2, which specifies safety and hygiene requirements for machines used to prepare and process food, to eliminate or reduce the risk of infection, and assesses the risks to be considered in terms of hazards (for service and food), it also defines the requirements for the construction materials, joints and surfaces, depending on their area of application, with particular emphasis on the food zone.

2. Ensuring safety and limiting the risk level of machines - requires the application of the so-called a safety triad based on the construction and production of safe machines from the very premise in which the risks associated with any hazards have been eliminated or reduced to a minimum. The hazards eliminated refer e.g. to any mechanical, electrical, thermal, chemical or even noise hazards. If there is a risk that cannot be eliminated at this level, the manufacturer applies additional protective measures such as covers and protective devices. The above activities never reduce the risk of threat to zero, it always exists to a lesser or greater extent, about which manufacturers (in the operating instructions and through appropriate markings and pictograms) inform and warn every machine users. In addition, instructions for machinery used in the food, cosmetics and pharmaceutical industries must indicate the recommended cleaning, disinfecting and rinsing agents, not only for easily accessible areas, but also for those areas to which it is not available or not recommended.

3. Recommendations for users of machines and devices in operation - safety should be ensured by their proper use in accordance with the manufacturer's instructions, maintaining the proper technical condition of the machine, and depending on the existing conditions, also applying additional technical safety measures to reduce or eliminate the hazard during operation.

\subsection{Dangerous factors and safety measures in food industry machines}

The most dangerous in machines are the moving parts related to the process, as well as all moving parts that carry the machine power. The Machinery Directive indicates (point 1.3.8) that in order to improve safety, depending on the type of risk, shields and fences separating hazardous areas should be used. Safety protection devices enable building an effective and reliable security system ensuring high level of protection, in accordance with the requirements of the EU regulations (www.astat.pl).For example:

- monitoring device,

- opening control sensors (sensors that in the case of opening the cover cause the machine to stop, and an open guard prevents turning on the machine),

- safety limit switches, e.g. magnetic safety switches,

- curtains and safety barriers that belong to the electro-sensitive (non-contact) protective devices. They can complement, for example, the fencing system or work independently, and their task is to detect the presence of people and cases of intrusion into the danger zone. The interruption of the beams by the 
operator or bystander stops the hazardous elements. The choice of the curtain depends on from the height of the protected zone, resolution (protection of fingers, hands, body) and safety categories,

- devices activated by pressure on the working surface of the safety element, e.g. mats, bumpers, safety bars.

It should be noted that the person responsible for the application of actions and measures to minimize the risks associated with the operation of mechanical equipment is the employer (2009/104 / EC, Article 3). Therefore, for employers it is necessary to maintain organizational measures, such as training for machine operators, safe work methods promotion, usage of workplace instructions and the use of personal protective equipment. The employer is also obliged to carry out periodic reviews of the existing safety situation.

\section{CONCLUSION}

System management of Safety, Quality and Environment of production enterprises in the food industry is the obligatory condition of entrepreneurial activity. The selected determinants of quality and safety management presented in the article point to normative EU and national formalized quality management systems ISO 22000 / HACCP and food safety FSMS. In the food industry, the role of traditional competences based on costs and capital is decreasing, and the importance of qualitative factors and the implementation of broadly understood innovations is growing. The application of quality management systems has become an indispensable condition for the functioning of the food industry enterprise and for building its brand. Conducting activities in accordance with the requirements of ISO 22000 / HACCP confirms that the company offers healthy and safe products.

\section{REFERENCE}

Andersson A, 2019, The trade effect of private standards, European Review of Agricultural Economics 46/2, pp. 267-290

Barkema, H.W., von Keyserlingk, M.A.G., Kastelic, J.P., Lam, T.J.G.M., Luby, C., Roy, J.-P., LeBlanc, S.J., Keefe, G.P., Kelton, D.F., 2015. Invited review: Changes in the dairy industry affecting dairy cattle health and welfare. Journal of Dairy Science, 98(11), 7426-7445. DOI: 10.3168/jds.2015-9377

Baryshnikova, N., Klimecka-Tatar, D., Kiriliuk, O., 2019. The role of the foreign trade in ensuring food security in the countries of the world: an empirical analysis. СzOTO 2019, 1(1), 867-874. DOI: 10.2478/czoto-2019-0111

Directive 2001/45/EC of the European Parliament and of the Council of 27 June 2001 amending Council Directive $89 / 655 /$ EEC concerning the minimum safety and health requirements for the use of work equipment by workers at work (second individual Directive within the meaning of Article 16(1) of Directive 89/391/EEC)

Directive 2006/42/EC of the European Parliament and of the Council of 17 May 2006 on machinery, and amending Directive 95/16/EC (recast) (Text with EEA relevance)

Directive 2009/104/EC of the European Parliament and of the Council of 16 September 2009 concerning the minimum safety and health requirements for the use of work equipment by workers at work (second individual Directive within the meaning of Article 16(1) of Directive 89/391/EEC)

Directive 89/391/EEC of the European Parliament and of the Council with the objective to introduce measures to encourage improvements in the safety and health of workers at work. It is described as a "Framework Directive" for occupational safety and health (OSH) by the European Agency for Safety and Health at Work 
Directive 89/655/EEC of the European Parliament and of the Council of 30 November 1989 concerning the minimum safety and health requirements for the use of work equipment by workers at work (second individual Directive within the meaning of Article 16 (1) of Directive 89/391/EEC)

Directive 95/16/EC of European Parliament and Council of 29 June 1995 on the approximation of the laws of the Member States relating to lifts

EN 1672-2 Food processing machinery - Basic concepts - Part 2: Hygiene requirements; EN 1672-2:2005+A1:2009

Fact Sheets on the European Union, 2019, Health and Safety at Work, www.europarl.europa.eu/factsheets/en

FSSC 22000. Food Safety System Certification 22000

ISO 22000:2005. Food safety management systems -- Requirements for any organization in the food chain.

ISO/TS 22002-1:2009. Prerequisite programmes on food safety -- Part 1: Food manufacturing

Khan, I., Tango, N.C., Miskeen, S., Lee, B.H., Oh, D.H., 2017. Hurdle technology: A novel approach for enhanced food quality and safety $-A$ review. Food Control 73, 1426-1444. DOI: 10.1016/j.foodcont.2016.11.010

Kielesińska A., 2018. Food quality and safety in the brewing industry. Production Engineering Archives 20, 16-19. DOI: 10.30657/pea.2018.20.04

Knop, K., Mikulová, P., 2019. Evaluation of the level of work safety, advancement and efficiency of the use of machines and devices on labelling and packaging line and an attempt to compare the results using the modified mckinsey matrix, CzOTO 2019, 1(1), 189-196. DOI: 10.2478/czoto-2019-0024

Martinsa, Z.E., Pinho, O., Ferreira, I.M.P.L.V.O., 2017. Food industry by-products used as functional ingredients of bakery products. Trends in Food Science \& Technology, 67, 106128. DOI: $10.1016 /$ j.tifs.2017.07.003

Nerín, D., Contín, E., Asensio, E., 2007. Kinetic migration studies using Porapak as solid-food simulant to assess the safety of paper and board as food-packaging materials. Analytical and bioanalytical chemistry, 387(6), 2283-2288

Piras, C., Roncada, P., Rodrigues, P.M., Bonizzi, L., Soggiu, A., 2015. Proteomics in food: Quality, safety, microbes, and allergens DOI: 10.1002/pmic.201500369

Pouliot, S., Sumner, D.A., 2008. Traceability, liability, and incentives for food safety and quality. American Journal of Agricultural Economics, 90(1), 15-27, DOI: 10.1111/j.14678276.2007.01061.x

Regulation (EC) No 1935/2004 of the European Parliament and of the Council of 27 October 2004 on materials and articles intended to come into contact with food and repealing Directives 80/590/EEC and 89/109/EEC

Rosak-Szyrocka, J., Begović Blažević, L., 2019. Food safety in quality mark aspect. CzOTO 2019, 1(1), 558-565. DOI: 10.2478/czoto-2019-0071

Yam, K.L., Takhistov, P.T., Miltz, J., 2005. Intelligent packaging concepts and applications, Journal of Food Science, 70, R1-R10, DOI: 10.1111/j.1365-2621.2005.tb09052.x.

Yaseen, T., Da-Wen Sun, Jun-Hu Cheng, 2017. Raman imaging for food quality and safety evaluation: Fundamentals and applications. Trends in Food Science \& Technology, 62, 177-189. DOI: 10.1016/j.tifs.2017.01.012 